\title{
EFICÁCIA DO PROGRAMA DE REGIONALIZAÇÃO DO TURISMO NAS REGIÕES TURÍSTICAS DO RIO GRANDE DO NORTE (2004-2014)
}

\section{EFFECTIVENESS OF THE TOURISM REGIONALIZATION PROGRAM IN THE TOURIST REGIONS OF RIO GRANDE DO NORTE (2004-2014)}

Renata Mayara Moreira de Lima ${ }^{1}$

UFAL: https://orcid.org/0000-0001-6093-4188

João Bosco Araújo da Costa ${ }^{2}$

UFRN: https://orcid.org/0000-0003-4421-728X

DOI: 10.21680/1982-1662.2021v4n31ID26413

\section{Resumo}

O objetivo desse artigo é apresentar e discutir alguns resultados encontrados em uma pesquisa que avaliou a implementação do Programa de regionalização do Turismo nas regiões turísticas do Rio Grande do Norte no recorte temporal de dez anos (20042014). Especificamente apresenta os resultados alcançados no âmbito regional, com base no critério de eficácia, que realiza a comparação entre o proposto e o cumprido em determinada política pública. 0 processo metodológico utilizado incluiu a elaboração de uma matriz de avaliação da implementação, com graus diferenciados de eficácia, além da revisão bibliográfica, pesquisa documental, coleta de dados secundários e pesquisa de campo com visitas aos municípios e regiões pesquisadas, com a realização de 26 entrevistas com atores diretamente envolvidos com a implementação do PRT no Rio Grande do Norte. Os resultados encontrados de acordo com os indicadores de avaliação mostram que a forma de elaboração dos planos de

\footnotetext{
${ }^{1}$ E-mail: renatammlima@gmail.com

2 E-mail: joaobac58@gmail.com
} 
desenvolvimento regionais deve ser revista, para que se insiram efetivamente os atores e realidades locais. Identificou-se que ações de cooperação realizadas nas regiões e a proposição de roteiros turísticos, são pontuais e contam com a predominância de alguns atores regionais. Verificou-se ainda que não existem esforços coordenados coletivos com o objetivo promocional das regiões e que não se tem conseguido coletar os dados necessários ao planejamento do turismo. Conclui-se que a baixa eficácia nos indicadores é decorrente principalmente da insuficiência de recursos materiais, humanos e financeiros disponíveis para a implementação.

Palavras-chave: Políticas Públicas de Turismo. Avaliação. Eficácia. Regiões Turísticas.

\section{Abstract}

The objective of this paper is to present and discuss some results found in a research that evaluated the implementation of the Tourism Regionalization Program in the tourist regions of Rio Grande do Norte in the ten-year period (2004-2014). Specifically, it presents the results achieved at the regional level, based on the criterion of effectiveness, which performs the comparison between what is proposed and what has been accomplished in a given public policy. The methodological process used included the elaboration of an implementation evaluation matrix, with different degrees of effectiveness, in addition to bibliographic review, documentary research, secondary data collection and field research with visits to the cities and regions surveyed, with the realization of 26 interviews with actors directly involved with the implementation of PRT in Rio Grande do Norte. The results found according to the evaluation indicators show that the form of elaboration of the regional development plans must be revised, so that the actors and local realities are effectively inserted. It was identified that cooperation actions carried out in the regions and the proposal of tourist itineraries, are punctual and have the predominance of some regional actors. It was also found that there are no collective coordinated efforts with the promotional objective of the regions and that it has not been possible to collect the necessary data for tourism planning. It is concluded that the low effectiveness of the indicators is mainly due to the insufficiency of material, human and financial resources available for implementation. 
Keywords: Public Tourism Policies. Evaluation. Effectiveness. Tourist Regions.

\section{Introdução}

No Brasil, as primeiras iniciativas de fomento ao turismo nacional mostraram-se pontuais e desarticuladas, datando da década de 1930. Apenas recentemente, especificamente a partir da década de 1960, sobretudo 1990, com a criação de algumas iniciativas, é que se pode falar no caso brasileiro, de um planejamento mais consistente e contínuo com relação à atividade turística. Um avanço em termos de maior sistematização da ação pública deu-se a partir de 2003, quando se criou o Ministério do Turismo (MTur) no governo de Luiz Inácio Lula da Silva (2003-2010).

Nesse contexto, foi criado um novo programa público, denominado como Programa de Regionalização do Turismo (PRT), considerado um desdobramento do Programa Nacional de Municipalização do Turismo (PNMT) da década anterior. Mudouse o foco do município para ser pensado na região enquanto objeto de intervenção. Sua execução deveria se dar de forma descentralizada e regionalizada, a partir de um planejamento coordenado e participativo, tendo como premissa para que isso pudesse ocorrer, a institucionalização de instâncias de governança (BRASIL, 2013).

Considerando a importância discursiva que foi colocada nesse Programa em âmbito federal, é que se atentou para a relevância de se fazer uma pesquisa avaliativa sobre o PRT no Rio Grande do Norte, já que se sabe que os estudos que avaliam políticas de turismo são escassos (LIMA, 2017). A pergunta norteadora da pesquisa foi mensurar quais os graus de eficácia que o PRT alcançou nas regiões turísticas do estado, no recorte temporal de dez anos (2004-2014), a saber: Polo Agreste/Trairi, Polo Costa Branca, Polo Costa das Dunas, Polo Seridó e Polo Serrano.

A pesquisa nessas regiões foi baseada na coleta de dados secundários, em análise documental e na seleção de uma amostra dentro de cada região para entrevistar especificamente alguns atores, que foram os responsáveis por dar subsídios para avaliar o PRT no âmbito regional. Escolhemos trabalhar dentro da perspectiva de uma avaliação de implementação de políticas, que é a mais adequada quando a política/o programa/ou o projeto avaliado ainda está em andamento.

O trabalho considera a afirmação de Draibe (2001) de que pesquisas de avaliação de implementação devem mapear os resultados alcançados pelas 
intervenções públicas, relacionando-os aos processos, isto é, pensar conjuntamente processos e resultados. Dentro dessa escolha, trabalhamos diretamente com o critério de eficácia - relação entre o previsto e o implementado em um dado programa (FIGUEIREDO; FIGUEIREDO, 1986). Nesse sentido, o objetivo do artigo é apresentar os resultados, com base na eficácia, que o PRT alcançou no recorte temporal 2004-2014 nas regiões turísticas do Rio Grande do Norte.

\section{Região e Regionalização no PRT}

A tônica da regionalização do turismo no Brasil, durante e após o Governo Lula, tem suas bases no Plano Nacional de Turismo (2003-2007), mas só foi lançado oficialmente em 2004, com o "Programa de Regionalização do Turismo - Roteiros do Brasil”.

Nesse programa, que é uma das principais diretrizes da política nacional de turismo do país, ratificado na Lei $\mathrm{n}^{\circ} 11.771$ de 17 de setembro de 2008, considera-se a região como um espaço geográfico que apresenta características e potencialidades similares e complementares, capazes de serem articuladas e que definam um território. Desse modo, a concepção centrada em apenas um município do PNMT, programa anterior ao PRT, modificou-se para incorporar a região.

Argumenta-se que o desenvolvimento local ou regional desencadeia novas relações sociais e políticas, através de uma reconstrução e nova apropriação do território. A categoria região turística é utilizada com o argumento de ser possuidora de maiores possibilidades para promover uma integração, articulação intersetorial e uma cooperação entre os atores envolvidos com o turismo, com o objetivo de ampliar e melhorar os produtos turísticos. Essa expansão possibilitaria, por outro lado, uma maior dinâmica econômica, com a criação de empregos e uma possível melhoria na renda das pessoas da região.

Regionalizar nesse Programa público significa um modelo de política pública “[...] descentralizada, coordenada e integrada, baseada nos princípios da flexibilidade, articulação, mobilização, cooperação intersetorial e interinstitucional e na sinergia de decisões." (BRASIL, 2004, p. 11). Para regionalizar considera-se necessário expandir a ação centrada na unidade municipal para um compartilhamento de ações e responsabilidades entre vários municípios, no entanto, sem desmerecer a escala local e a colocando em um novo lugar representativo. 
Regionalizar representa a criação de um ambiente que se espera ser democrático e participativo entre municípios e atores envolvidos. Brasil (2007a) afirma ainda que com a regionalização, o Brasil estaria se alinhando com tendências internacionais que almejam aproveitar melhor os recursos financeiros, técnicos e humanos, para que seja possível estruturar novos destinados turísticos mais qualificados e competitivos.

Pelo exposto nos documentos oficiais do PRT, não se estaria adotando a região como palco de ação, a desconsiderando de seu contexto e das relações complexas que fazem parte da sua constituição enquanto território. Esse é justamente um dos pontos pelos quais as políticas públicas de turismo vêm constantemente sofrendo críticas de geográficos, já que tradicionalmente as políticas do setor têm desconsiderado as complexas relações presentes do espaço (CRUZ, 2002, 2006; FRATUCCI, 2008, 2014).

Ademais, vem tendo crítica à própria consideração da categoria região como adequada ao planejamento do turismo, já que o turismo enquanto atividade econômica e prática social espraia-se de forma descontínua no território, em virtude dos atrativos turísticos estarem dispostos de forma aleatória e não ordenados, o que vai de encontro à noção de região (BOULLÓN, 2002).

Argumento semelhante utiliza Fratucci $(2008,2014)$ para criticar o Programa de Regionalização do Turismo Brasileiro, pois segundo o autor uma categoria mais adequada para se captar a espacialidade do fenômeno turístico tal como ele ocorre seria o de "território-rede", pois em virtude do turismo se materializar apenas em alguns pontos, os destinos turísticos estariam interligados em forma de redes. Pensar a partir dessa lógica permite que se incluam “[...] todos os seus agentes produtores, suas ações, interações e inter-relações, sejam elas complementares, concorrentes, sejam ou antagônicas" (FRATUCCI, 2014, p. 48).

Encontramos em Brasil (2007a) um aspecto significativo, que poderia ser considerado, se efetivamente colocado em prática, o preenchimento de uma lacuna, pelo menos em partes, dos questionamentos levantados por Boullón (2002) e Fratucci (2008, 2014), que é a consideração do que é a região turística. Segundo um dos documentos oficiais do PRT, esta ultrapassaria os limites geopolíticos definidos para o país e poderia incluir municípios de mais de um estado ou até mesmo de países diferentes. 
E ainda afirma-se que dentro de uma região turística nem todos os municípios são turísticos, no entanto, ressalta-se que estes podem participar da rede de regionalização a partir de suas peculiaridades. Assim, se um município tem como principal atividade econômica a agropecuária, este pode participar da regionalização ao fornecer leite, carne, queijo, ou outro produto, a um município turístico que tenha necessidade desses artigos em virtude da demanda turística expandida. Essa seria uma forma de integrar os municípios que “[...] sempre ficaram à margem da implementação de políticas públicas. Por meio do desenvolvimento regional, esses municípios poderiam se beneficiar, de alguma forma, da atividade turística” (BRASIL, 2007a, p. 19).

$\mathrm{Na}$ prática não é isso que tem se verificado. Não se encontra, no Mapa do Turismo Brasileiro, regiões turísticas que envolvam mais de um estado e nem municípios não turísticos que têm conseguido efetivamente se inserir dentro da proposta de regionalização da qual fazem parte. Apesar da perspectiva regional do Programa, a atividade turística tem acontecido essencialmente em municípios centrais, como as capitais, sem maiores benefícios nos municípios vizinhos e sem conseguir se fortalecer no interior do país. São inúmeros os obstáculos a implementação desse Programa público, como veremos, logo mais.

\section{Avaliação de Implementação de Políticas Públicas}

A avaliação de políticas públicas enquanto pesquisa constituiu-se em um exercício que busca estabelecer uma relação de causalidade entre os resultados de uma política e suas ações, no sentido de averiguar em que medida a política conseguiu atingir os resultados esperados e de que forma isso gerou consequências no contexto social em que ela foi implementada/executada.

De acordo com Draibe (2001), as avaliações respondem a distintos objetivos, como os objetivos de conhecimento, pela relação de meios e resultados; objetivos de verificação dos retornos dos programas, utilizando-se os critérios de eficácia, eficiência e efetividade; e objetivos pragmáticos, quando se busca que a avaliação seja utilizada para a detecção e correção de falhas nos programas.

O timing é um aspecto importante da avaliação e refere-se ao momento em que esta é realizada, podendo ser considerada de dois tipos, a ex ante e a ex post (DRAIBE, 2001; COHEN; FRANCO, 2011). A ex ante é a que pode ser realizada antes 
mesmo do início da implementação do programa e tem como objetivo verificar se de acordo com o desenho do programa será possível atingir os objetivos pretendidos, ou seja, tem como finalidade melhorar as chances de o programa ter sucesso. Além de que, contribui para a obtenção de um ponto de partida que ajuda em futuras comparações. Por sua vez, a avaliação ex post possui de acordo com Draibe (2001) dois objetivos: 1) verificar os graus de eficiência e eficácia com que o programa atende aos objetivos, e 2) verificar a efetividade do programa. Pode ser realizada tanto durante a implementação quanto após o término de suas ações.

O timing da avaliação influencia na caracterização de sua natureza, que pode ser: de resultados ou de processo/implementação. Segundo Cohen e Franco (2011), essas avaliações se diferenciam principalmente pelos problemas que respondem, a de resultados questiona se o programa em questão cumpriu com seus objetivos e quais os produtos, os efeitos e os impactos de suas ações.

Já a avaliação de processos é realizada durante a implementação do programa, com o objetivo de verificar se as ações que estão sendo implementadas estão de acordo com os fins perseguidos. Refere-se nos termos de Cohen e Franco (2011) a uma avaliação periódica. Para Draibe (2001) esse tipo de avaliação tem a pretensão de detectar os problemas que dificultam ou podem dificultar a implementação da política e está mais diretamente ligada ao desenho do programa.

É relevante destacar que a avaliação só pode ser operacionalizada mediante critérios que podem ser bastante diversos, a depender dos objetivos que se busca alcançar. Arretche (2009) define, baseada em Figueiredo e Figueiredo (1986), esses critérios como: 1) a eficácia é a relação entre o previsto e implementado, podendo ser entre objetivos propostos e conseguidos, e entre instrumentos previstos e alcançados; 2) a eficiência é a relação entre os recursos empregados e os resultados conseguidos, na proposição do menor custo para o maior benefício; e 3) a efetividade é a dimensão que permite verificar se os resultados mais amplos do programa na realidade social foco da intervenção foram alcançados.

0 que permite operacionalizar esses critérios de avaliação expostos anteriormente é a escolha de indicadores, que conforme Januzzi (2005) permitem: operacionalizar um conceito abstrato ou uma demanda de interesse pragmático; aproximar em termos mais operacionais dimensões de interesse definidas ao se fazer escolhas teóricas ou políticas; subsidiar atividades de planejamento público e de 
formulação de políticas públicas; monitorar as condições de vida e bem-estar da população e aprofundar a investigação científica sobre a transformação social e sobre influenciadores de diversos fenômenos que ocorrem no contexto social.

\section{Metodologia}

0 recorte territorial da pesquisa constituiu-se nas cinco regiões turísticas do Rio Grande do Norte, definindo-as a partir do Mapa de Regionalização do Turismo Brasileiro. Levando em consideração que dentro do recorte temporal da pesquisa (2004-2014) existiram quatro mapas, 2004, 2006, 2009 e 2013, optamos por utilizar o recorte dos municípios presentes no mapa de 2013, por se aproximar do recorte final do tempo da avaliação, com exceção do Polo Serrano, que por não aparecer nesse mapa, em virtude de um erro operacional de não envio dos dados do polo pela Secretaria Estadual de Turismo (Setur/RN) para o MTur, utilizamos o recorte do mapa anterior, o de 2009. Dessa forma, o recorte territorial das cinco regiões turísticas foi composto por 92 municípios.

Para a compreensão da realidade estudada, além da revisão de literatura, procedeu-se a pesquisa documental, junto aos órgãos responsáveis pelo PRT: em âmbito federal, através dos documentos oficiais do Programa produzidos pelo MTur; em âmbito regional, com as regiões turísticas, coletando-se as atas referentes às reuniões dos conselhos de turismo durante o recorte temporal da pesquisa; em âmbito estadual, na Setur, para se conseguir acesso aos Planos de Desenvolvimento Integrado do Turismo Sustentável (PDITS) das cinco regiões turísticas; e em âmbito municipal, nas Secretarias de Turismo dos municípios inclusos na pesquisa.

$\mathrm{Na}$ pesquisa de campo, optamos pela adoção de uma amostra intencional, inserindo os principais atores que estavam sendo mobilizados durante o processo de implementação, que eram aqueles que se faziam presentes nas reuniões das instâncias de governança, que no caso do Rio Grande do Norte são os conselhos de turismo regionais. Esse foi o primeiro critério de escolha e que é levado em consideração nos critérios criados posteriormente. Para isso, foi necessário mapear as presenças dos atores nas atas dos conselhos, fossem estes municípios ou membros em geral. A contabilização das presenças nas atas considerou o período temporal desde a concepção das regiões até o ano de 2014. Assim, a coleta das atas contempla os seguintes períodos: Polo Agreste/Trairi (2009-2014) - 7 atas; Polo Costa Branca (2005- 
2014) - 13 atas $^{3}$; Polo Costa das Dunas (2005-2014) ${ }^{4}-36$ atas; Polo Seridó (2005-2014) $)^{5}$ - 23 atas, e Polo Serrano (2008-2014) - 15 atas, gerando um quantitativo de 94 atas.

Dentre os mais participativos nas reuniões, procedeu-se como segundo critério a escolha de representantes municipais, no que foi adicionado, além dos mais participativos, à relevância regional do município na atividade turística. Dessa forma, os municípios escolhidos para participar da pesquisa foram: Polo Agreste/Trairi (Santa Cruz); Polo Costa Branca (Guamaré e Areia Branca); Polo Costa das Dunas (Extremoz, Tibau do Sul e Natal); Polo Seridó (Acari e Caicó) e Polo Serrano (Martins).

Como terceiro critério de escolha, procedeu-se a identificação dos demais membros dos conselhos que pudessem ser entrevistados dentro de uma visão mais abrangente da região turística. Escolhemos as instituições que fazem parte de todas as regiões turísticas e realizamos quatro entrevistas: representado pela 1) Setur (duas entrevistas com pessoas diferentes, uma exploratória ainda em 2015 e uma já com os indicadores avaliativos em 2016); 2) a Empresa Potiguar de Promoção Turística (Emprotur) e 3) o Serviço Brasileiro de Apoio às Micro e Pequenas Empresas (Sebrae) unidade Natal. Além disso, em cada conselho de turismo, entrevistamos as secretarias executivas, que estão à frente de cada uma dessas instâncias de governança.

Por fim, decidimos acrescentar, um ou dois atores a serem entrevistados para cada região, verificando quais eram os atores (órgãos públicos, iniciativa privada, sociedade civil e instituições de ensino) que possuíam mais de $60 \%$ de participação nas reuniões dos respectivos conselhos. No entanto, não levamos em consideração só a presença, mas também os que fossem indicados ao longo do processo como representativos por aqueles que iam sendo entrevistados (principalmente a secretaria executiva). Ao final do trabalho de campo, 26 atores envolvidos diretamente com a implementação do PRT no RN foram entrevistados.

Nesse sentido, a pesquisa considerou durante a coleta dos dados quatro eixos de avaliação do PRT para mensurar os indicadores relacionados à implementação: 1) Criação das regiões turísticas; 2) Criação das instâncias de governança, 3) Ações no âmbito regional e 4) Ações no âmbito municipal. Nesse artigo, compartilharemos os

\footnotetext{
${ }^{3}$ Tivemos dificuldade em conseguir as atas do Polo Costa Branca, em virtude de algumas destas terem sido extraviadas. Conseguimos ter acesso a 13 atas em comparação a 26 reuniões que devem ter ocorrido desde a constituição da região até 2014 , o que corresponde a 50\% do total.

${ }^{4} \mathrm{O}$ Polo Costa das Dunas tem existência anterior ao PRT, no entanto, optamos por analisar as atas a partir de 2005, recorte temporal que se aproxima dos demais polos.

${ }^{5}$ Não tivemos acesso às duas últimas atas do período analisado referentes ao Polo Seridó a tempo de considerá-las na contabilização das presenças ( $21^{\mathrm{a}}$ e $22^{\mathrm{a}}$ reunião).
} 
principais resultados encontrados com base na aplicação da Matriz no que tange ao terceiro eixo, levando em consideração os graus de realização, como mostra o quadro a seguir:

Quadro 1: Eficácia do PRT nas regiões turísticas quanto às ações de âmbito regional

\begin{tabular}{|c|c|}
\hline $\begin{array}{c}\text { Indicadores de } \\
\text { implementação - eficácia }\end{array}$ & Graus de realização \\
\hline \multirow{4}{*}{$\begin{array}{l}\text { Elaboração, implementação e } \\
\text { avaliação dos planos } \\
\text { estratégicos regionais. }\end{array}$} & Alto: Elaborado, implementado e avaliado. \\
\hline & Médio: Elaborado e implementado. \\
\hline & Baixo: Elaborado. \\
\hline & Ineficaz: Não elaborado. \\
\hline \multirow{4}{*}{$\begin{array}{l}\text { Elaboração, implementação e } \\
\text { avaliação de roteiros ou outros } \\
\text { projetos coletivos. }\end{array}$} & $\begin{array}{l}\text { Alto: A partir de dois roteiros turísticos ou outros projetos } \\
\text { coletivos elaborados, implementados e avaliados. }\end{array}$ \\
\hline & $\begin{array}{l}\text { Médio: 1) A partir de um roteiro turístico ou outros } \\
\text { projetos coletivos elaborados, implementados e } \\
\text { avaliados. Ou 2) A partir de dois roteiros turísticos ou dois } \\
\text { projetos coletivos elaborados e implementados. }\end{array}$ \\
\hline & $\begin{array}{l}\text { Baixo: 1) A partir de um roteiro turístico ou um projeto } \\
\text { coletivo elaborado e implementado. Ou } 2 \text { ) Roteiros } \\
\text { turísticos ou outros projetos coletivos (qualquer } \\
\text { quantidade) apenas elaborados. }\end{array}$ \\
\hline & $\begin{array}{l}\text { Ineficaz: Não há roteiros, nem outros projetos coletivos } \\
\text { elaborados. }\end{array}$ \\
\hline \multirow{4}{*}{$\begin{array}{l}\text { Elaboração, implementação e } \\
\text { avaliação do plano de } \\
\text { marketing ou utilização de } \\
\text { outros mecanismos de } \\
\text { marketing. }\end{array}$} & $\begin{array}{l}\text { Alto: Plano de Marketing elaborado, implementado e } \\
\text { avaliado. }\end{array}$ \\
\hline & Médio: Plano de Marketing elaborado e implementado. \\
\hline & $\begin{array}{l}\text { Baixo: 1) Plano de Marketing elaborado. Ou 2) Utilização } \\
\text { de mecanismos de marketing diversos. }\end{array}$ \\
\hline & $\begin{array}{l}\text { Ineficaz: Não há plano, nem utilização de mecanismos de } \\
\text { marketing. }\end{array}$ \\
\hline \multirow{4}{*}{$\begin{array}{l}\text { Sistematização de informações } \\
\text { sobre evolução do turismo }\end{array}$} & $\begin{array}{l}\text { Alto: Coleta e armazenamento dos dados de forma } \\
\text { contínua. }\end{array}$ \\
\hline & $\begin{array}{l}\text { Médio: Coleta e armazenamento dos dados de forma } \\
\text { esporádica. }\end{array}$ \\
\hline & $\begin{array}{l}\text { Baixo: Coleta e armazenamento de dados quando } \\
\text { necessário. }\end{array}$ \\
\hline & Ineficaz: Não há coleta e armazenamento de dados. \\
\hline
\end{tabular}

Fonte: Lima (2017).

\section{Eficácia do PRT nas regiões turísticas do RN}

0 primeiro indicador do eixo de avaliação - Elaboração, implementação e avaliação dos planos estratégicos regionais - centrou-se em identificar se as regiões turísticas do Rio Grande do Norte elaboraram o principal instrumento de planejamento do turismo para um determinado território, que é um plano de desenvolvimento, 
conforme prevê Brasil (2013), bem como verificou se esse plano foi implementado e passa por monitoramento e avaliação.

Verificamos que no período da pesquisa (2004-2014) foram elaborados três PDITSs. Esses foram os do Polo Costa Branca, do Polo Costa das Dunas e do Polo Seridó, preparados a partir de 2009 e entregues em 2011, para a contratação do Programa de Desenvolvimento do Turismo (Prodetur), de âmbito Nacional. Em virtude da não assinatura desse programa, os projetos desses planos foram parcialmente implementados. Nos casos dos Polos Agreste/Trairi e Polo Serrano, os PDITSs foram elaborados e entregues em 2016, com recursos do Projeto RN Sustentável. ${ }^{6}$

Sobre a elaboração desses documentos, notou-se uma cobrança muito grande por parte das regiões turísticas para que a Setur/RN criasse os mecanismos para implementar as ações propostas nos PDITSs, o que não aconteceu conforme se esperava, gerando uma descrença por parte dos atores regionais de que as ações propostas nesses documentos serão efetivadas, conforme o depoimento do Polo Costa Branca: "Há muita promessa, 'a partir de mês tal vai haver investimento', essa questão da interiorização do turismo, que eu acho que é muita conversa, falta muita prática, sabe?"7. No Polo Seridó, o representante entrevistado também aborda esse aspecto: "Já tem muito documento, muito planejamento, muita coisa no papel, mas as ações dependem de recursos financeiros." 8

A não implementação rápida desses planos gera outro agravante, que é a desatualização dos dados e dos projetos presentes nesses documentos. Isso aconteceu nos casos dos PDITSs do Polo Costa Branca, Polo Costa das Dunas e Polo Seridó, sendo preciso que estes passassem por uma atualização para que pudessem ser financiados pelo Banco Mundial através do RN Sustentável. Um dado ainda mais grave é que as informações coletadas no início de elaboração desses documentos ficam desatualizadas antes deles estarem prontos. Esse fato aparece na ata da $2^{\text {a }}$ Reunião Extraordinária do Polo Costa Branca (02 de junho de 2011), quando se menciona que os dados coletados em 2009 para a elaboração do diagnóstico referente a essa região

\footnotetext{
${ }^{6}$ Projeto RN Sustentável: Resultado de um acordo de empréstimo entre o Banco Internacional para Reconstrução e Desenvolvimento - Banco Mundial e o Governo do Estado do Rio Grande do Norte, com o objetivo de aumentar o dinamismo socioeconômico do estado e apoiar ações de modernização da gestão do setor público.

${ }^{7}$ Representante do Polo Costa Branca, em entrevista concedida em 12 jul. 2016.

${ }^{8}$ Representante do Polo Seridó, em entrevista concedida em 08 jul. 2016.
} 
turística já se encontravam defasados naquele momento em que o PDITS deveria ser aprovado pelo Conselho de Turismo, dois anos depois do início da elaboração.

Além desse aspecto, devem-se mencionar as prerrogativas participativas e inclusivas que devem nortear a construção desses documentos. Identificamos que as consultorias ${ }^{9}$ responsáveis pela elaboração, já que a Setur não possui o corpo técnico necessário para desenvolver essa ação, procedem à realização de oficinas com os conselheiros e municípios participantes da região, que devem, posteriormente, aprovarem ou não os produtos gerados nos Conselhos. No entanto, verificamos alguns problemas durante esse processo, que foi a realização de oficinas rápidas, sem o aprofundamento necessário das discussões. Essa evidência aparece na ata da $46^{\mathrm{a}}$ Reunião do Conselho de Turismo do Polo Costa das Dunas (18 de agosto de 2009).

Outra evidência que encontramos é que a ausência de aprofundamento também ocorre no momento de aprovação dos PDITSs nas reuniões dos Conselhos de Turismo. Esse último elemento mencionado também aparece nas atas do Conselho de Turismo do Polo Costa das Dunas, como na 54a Reunião (31 de maio de 2011). Ademais, pudemos acompanhar de perto esse processo, no que se refere às aprovações das versões finais dos PDITSs do Polo Agreste/Trairi e Polo Serrano, com a observação não participante realizada durante pesquisa de campo em 2016, quando verificamos que as aprovações dos referidos documentos se deram sem discussões profundas, notando-se algumas vezes que alguns conselheiros não leram a versão final do documento, tendose como consequência um esvaziamento do debate, sem proposição de melhorias nem questionamentos sobre aspectos que não ficaram claros. Sobre a rapidez com que o processo ocorre, encontra-se como justificativa o fato de que o recurso disponibilizado para essa construção conjunta tem um prazo, geralmente curto, em que precisa ser utilizado, sob pena de ficar indisponível.

Nos PDITSs mais recentes, do Polo Agreste/Trairi e Polo Serrano, verificou-se que a produção acelerada desses documentos gerou problemas, inclusive de redação. No caso do Polo Agreste/Trairi, alguns conselheiros mencionaram o fato de existir trocas de nomes em partes do texto, aparecendo ao invés do nome dessa região turística o nome do Polo Serrano, o que também comprovamos quando procedemos à leitura desse PDITS.

\footnotetext{
9 1) Consultoria responsável pela elaboração do PDITS do Polo Costa Branca, Polo Costa das Dunas e Polo Seridó: START Pesquisa e Consultoria Técnica Ltda.; 2) Consultoria responsável pela elaboração do PDITS do Polo Agreste/Trairi e Polo Serrano: ITEC Infraestrutura, Tecnologia, Engenharia, Consultoria.
} 
Um último aspecto que apareceu na pesquisa como relevante e vinculado a esse indicador foi o próprio fato de se utilizar consultorias na elaboração dos PDITSs. Os conselheiros que se atentaram para essa questão destacam o volume de recursos gastos através dessas empresas: "[...] milhões e milhões só de uma empresa de fora, porque ela pode trabalhar a gente aqui, gastando o mínimo, se desse uma condição boa em parceria com as instituições de ensino. Eu acho que não precisava de outra equipe técnica." 10

Além disso, os conselheiros afirmam que essas consultorias não conhecem as realidades pesquisadas: "[...] ele pega uns questionários que nem se adequam à realidade que eles estão muitas vezes. [...] Por exemplo, aqui e em Santa Cruz nós tínhamos que aplicar se a população gostava de fazer passeio de bugue." 11

A partir desses aspectos mencionados, consideramos a eficácia dos PDITSs do Polo Costa Branca, Polo Costa das Dunas e Polo Seridó como baixa em virtude de poucas ações terem obtido financiamento. Por sua vez, consideramos os casos do Polo Agreste/Trairi e Polo Serrano como ineficazes, devido à elaboração dos PDITSs dessas regiões estarem fora do recorte temporal considerado na pesquisa.

Referente ao segundo indicador desse eixo - Elaboração, implementação e avaliação de roteiros ou outros projetos coletivos-, buscamos verificar se a constituição das regiões turísticas e dos seus respectivos Conselhos de Turismo, no caso do Rio Grande do Norte, produziu resultados concretos, seja na organização de roteiros, seja através de iniciativas de cooperação.

No caso do Polo Agreste/Trairi, referente aos roteiros turísticos, conseguimos perceber o desenvolvimento de ações pontuais, como a criação pelo Sebrae de um roteiro específico para o município de Santa Cruz chamado "Rota da Fé", além do planejamento de um roteiro intitulado "Paraísos do Agreste", que se constitui num consórcio integrado de três municípios: Passa e Fica, Serra de São Bento e Monte das Gameleiras. O roteiro "Paraísos do Agreste" foi criado pelo Sebrae e o estado também participa, através da Setur, com o objetivo de continuar o trabalho e desenvolver uma experiência que possa ser multiplicada. Os recursos para o desenvolvimento desse projeto foram oriundos do RN Sustentável.

Ademais, quando questionamos aos atores do Polo Agreste/Trairi sobre outros projetos coletivos, foi citada uma ação pontual de participação em uma feira de

\footnotetext{
${ }^{10}$ Representante do Polo Serrano, em entrevista concedida em 13 set. 2016.

${ }^{11}$ Representante do Polo Agreste/Trairi, em entrevista concedida em 14 set. 2016.
} 
negócios, na qual os municípios do polo dividiram um estande.

No caso do Polo Costa Branca, havia no início de implementação do PRT uma proposta de roteirização turística para a região que começou a ser formatada em 2006 e elaborada através de convênio da Setur com o MTur, no qual foi contratada via licitação uma consultoria especializada de Minas Gerais, a Creato. Os municípios que faziam parte dessa proposta eram seis: Mossoró, Macau, Guamaré, Açu, Areia Branca, Apodi e São Rafael. Esse acontecimento foi identificado através da análise das atas, no entanto, não conseguimos saber, se a proposta foi de fato concluída, já que não tivemos acesso a todas as atas do período e os entrevistados não se referiram à criação desse roteiro. Do mesmo modo, os atores sociais dessa região não identificaram nenhum outro formalmente constituído.

No que tange aos possíveis projetos de cooperação, todos os atores entrevistados desse polo não elencaram nenhuma ação. Especificamente na leitura das atas, identificamos um projeto conjunto que foi realizado através do Conselho do polo, que foi a proposição de um Curso de Guia de Turismo Regional oferecido pelo Senac com o apoio do governo do estado e dos municípios.

O caso do Polo Costa das Dunas é diferente dos demais polos porque possui um fluxo de turistas regular e alguns roteiros comercializados diretamente por agências. Fora essas ações realizadas por aqueles que já comercializam a região, acontecem ações pontuais entre os municípios, como aquelas ligadas a comercialização.

Referente aos demais projetos de cooperação, o que encontramos nas atas e que foi passado durante a realização de entrevistas, referem-se à formação dos grupos de trabalho ${ }^{12}$ no Conselho do polo, como uma forma de atuação conjunta por parte de diversas entidades e municípios, o que funcionou durante um determinado tempo. Inclusive aparece na ata da $30^{\mathrm{a}}$ Reunião Ordinária do Conselho, do dia 28 de junho de 2016, a formação de um grupo intitulado “Operacionalização para o Desenvolvimento Turístico", que foi uma proposta dos municípios para a atuação em conjunto em assuntos do seu interesse, não se notando, posteriormente, resultados de projetos que tenham sido desenvolvidos por esse grupo.

Foram citadas ainda pelos entrevistados outras ações de parceiras como: campanha realizada contra a exploração sexual infantojuvenil; as capacitações realizadas através do Prodetur; projeto chamado Operação Verão e projeto sobre

\footnotetext{
${ }^{12}$ Os grupos temáticos funcionaram até um determinado tempo também no Polo Seridó. No Polo Costa Branca e no Polo Serrano, eles foram propostos, mas não houve dinamização.
} 
resíduos sólidos. Identificamos também através das atas a elaboração de um roteiro pedestre para a Ribeira e a Cidade Alta, no qual houve a participação das instituições de ensino superior do Conselho para a sua constituição. Fora essas ações, não existem projetos.

No caso do Polo Seridó, verificou-se que existiu nessa região a proposição do "Roteiro Seridó", em 2005, que o Sebrae esteve à frente, a partir de um convênio com a Setur, no qual estavam envolvidos oito municípios: Acari, Caicó, Carnaúbas dos Dantas, Cerro Corá, Currais Novos, Jardim do Seridó, Lagoa Nova e Parelhas. As propostas de roteirização do Seridó estavam pautadas na religiosidade, na cultura e no artesanato, na gastronomia e na caatinga e arqueologia, formando a partir disso diversos roteiros. Esse projeto encontra-se concluído, tendo gerado nos atores participantes uma mobilização significativa quando da participação no processo.

Junto com o Roteiro Seridó, foi também organizado pelo Sebrae o projeto “Cama, Café e Rede", com o objetivo de expandir a capacidade de hospedagem da região, utilizando as moradias dos residentes como pontos de acolhimento e hospitalidade, o que também se caracterizava como um turismo mais inclusivo e de base local. No entanto, tal projeto paralisou, como indica a fala a seguir: "Então o roteiro nem se fala mais. Se você pegar no site ele está desatualizado. Quer dizer, aquele projeto 'Cama, Café e Rede' também não existe mais. Uma casa ou outra ainda existe. Iniciativa própria. Então, não há!”. ${ }^{13}$

As iniciativas que persistem são individuais e não representam dinamismo para as localidades. Referente às demais parcerias que possam ter sido criadas nessa região, foi nos informado de uma realizada pelo Sebrae e Agência de Desenvolvimento do Seridó (Adese), integrantes do Conselho de Turismo do Polo Seridó, para a inscrição do Roteiro Seridó no Projeto Talentos do Brasil Rural, que tinha o objetivo de inserir o turismo rural e a agricultura familiar em roteiros a serem ofertados durante a Copa do Mundo em 2014, sendo essa região do Rio Grande do Norte uma das escolhidas para fazer parte desse projeto.

Ademais, nesse polo, citam-se parcerias pontuais realizadas com o Sebrae e o Senac no âmbito da capacitação, a partir da oferta de cursos profissionalizantes de turismo. Também foi citada uma parceria realizada através do conselho, em Carnaúba dos Dantas com o Instituto do Patrimônio Histórico e Artístico Nacional (Iphan), no

\footnotetext{
${ }^{13}$ Representante do Polo Seridó, em entrevista concedida em 08 jul. 2016.
} 
qual se construiu passarelas nos sítios arqueológicos desse município. Além de parcerias realizadas com a UFRN, campus Currais Novos, através do curso de turismo, nas quais já se criou o Plano Municipal de Turismo de Currais Novos e o inventário de toda a oferta turística do Seridó, entre outras ações.

No Polo Serrano, não se identificou nenhum roteiro turístico elaborado a partir da implementação do PRT. O único aspecto referente a isso aparece na ata da $6^{a}$ Reunião Ordinária, do dia 28 de abril de 2011, que foi uma proposta de roteirização entregue em forma de ofício por membros do Conselho à Setur, em que se propunha um roteiro integrando os municípios de Portalegre, Martins, Patu, Pau dos Ferros e Luís Gomes, no que nas atas seguintes não se tem nenhum encaminhamento.

Fora isso, encontrou-se uma ação que surgiu a partir da busca por resultados práticos que não estavam sendo visualizados pelos atores participantes da regionalização do turismo nessa região: a formação de um grupo, que possui tanto atores que fazem parte do Conselho quanto atores que estão fora desse processo, e chama-se Circuito das Serras Potiguares. Esse grupo passou a se reunir a partir de fevereiro de 2015 e considera o diálogo com as comunidades dos municípios que fazem parte do Alto e Médio Oeste Potiguar uma forma de mobilizar o turismo. A partir do reconhecimento por parte da Setur, o grupo foi chamado e passou a fazer parte do Conselho de Turismo da região, com direito a voto nas discussões que estão sendo empreendidas.

Sobre outras parcerias que tenham sido realizadas a partir da constituição dessa região turística e da formação do seu conselho gestor, nos foi citada a implementação do teleférico de Martins, o qual ainda estava em planejamento no momento da coleta de dados. Além disso, encontramos nas atas a proposição de um circuito gastronômico para a região entre Portalegre, Martins e Pau dos Ferros a partir da realização de festivais, no que também não percebeu-se efetivação da proposta.

Sobre esses resultados temos algumas observações. A primeira é que todas as ações desenvolvidas são pontuais e contam com poucas instituiçõos envolvidas. Quando se verifica alguma ação de cooperação, envolve no máximo três entidades e não passam por um processo de avaliação após serem colocadas em prática. Notou-se uma predominância do Sebrae, Senac e instituições de ensino, a exemplo da UFRN, propondo projetos em que os demais membros da região se envolvem. Sobre a pouca 
integração dos municípios, encontrou-se que: “Não existem projetos porque os municípios não trabalham conjuntamente." 14

Em posse desses resultados, no caso do Polo Agreste/Trairi e Polo Costa Branca a eficácia nesse indicador é baixa. No Polo Costa das Dunas e Polo Seridó, a eficácia é média. No Polo Serrano o indicador é considerado ineficaz.

O terceiro indicador desse eixo - Elaboração, implementação e avaliação do plano de marketing ou utilização de outros mecanismos de marketing - que se enquadra na verificação de utilização ou não de estratégias de promoção e comercialização dos produtos nas regiões turísticas do Rio Grande do Norte, proposto no âmbito do PRT como um módulo específico (Brasil, 2007b) e como objetivo específico e eixo de atuação em Brasil (2013). De forma específica, nos atemos a verificar se algum plano de marketing havia sido elaborado ou se eram utilizados outros mecanismos de marketing para promover as regiões e municípios.

No primeiro momento, verificamos que não existia plano de marketing preparado no período da pesquisa (2004-2014), porém, este estava ainda em processo de construção pela consultoria Solimar International com recursos do Projeto RN Sustentável.

Quando há ausência de um plano maior que oriente as ações de divulgação realizadas, acaba se utilizando de ações promocionais diversas, no que são mostradas as potencialidades das regiões. Referente a isso e observando as ações promocionais da Emprotur, em âmbito nacional e internacional, constatamos durante a pesquisa que a divulgação das regiões e municípios do Rio Grande do Norte não se dá de forma homogênea nos eventos e feiras que o estado participa, sendo priorizados aqueles municípios que possuem condições de receber turistas, o que fica evidente com a fala da representante estadual, quando coloca que se tenta "promover os interiores que tem a capacidade de recepção um pouco já estabelecida".

No que diz respeito a esse aspecto, percebeu-se durante a análise das atas e das entrevistas que os atores das demais regiões do Rio Grande do Norte acreditam que há uma priorização de Natal e região do entorno, do Polo Costa das Dunas, nas ações promocionais desenvolvidas pelo estado, como é possível verificar no depoimento a seguir: “[...] falei também que eles davam muita ênfase só para a capital e os polos do interior, os demais polos não têm a mesma propaganda, não tem

\footnotetext{
${ }^{14}$ Representante do Polo Costa das Dunas, em entrevista concedida em 12 set. 2016.
} 
o outdoor [...]". ${ }^{15}$ Outro entrevistado afirma que solicitou à Setur a mudança da forma como a divulgação acontece: “[...] coloquem no estande 'Rio Grande do Norte' ao invés de 'Natal - Rio Grande do Norte', coloquem 'Estado do Rio Grande do Norte, pelo amor de Deus'. Eu costumo dizer que o Rio Grande do Norte termina em Macaíba."16

Em virtude desse contexto, os membros dos Conselhos das regiões turísticas cobram por ações direcionadas de marketing por parte do estado para cada região turística. Sobre isso, nos foi informado durante a pesquisa que no caso das feiras nacionais de turismo, a Setur/Emprotur apresenta alguns pontos do interior do estado, aqueles que já possuem as condições de recepção. No entanto, nos eventos internacionais, argumenta-se que isso não é possível, quando a ênfase recai sobre Natal.

Nesse contexto, buscamos verificar se as regiões turísticas utilizavam outras formas de divulgação independentes. Constatamos que no início da implementação do PRT existiu um movimento de organização das regiões para a divulgação, o que parece não ter tido continuidade. Por exemplo, na ata da XIII Reunião Ordinária do Conselho do Polo Seridó (15 de dezembro de 2010), tem-se como pauta a apresentação da marca da região. No Polo Costa Branca, a aprovação da logomarca, a confecção de material de folheteria e a aprovação da criação do site relativo a essa região turística aparecem como temáticas na ata da $5^{\circ}$ Reunião Ordinária do Conselho (28 de setembro de 2007). No Polo Costa das Dunas, a pauta da criação de um site para essa região também aparece em algumas reuniões, como na ata da $31^{\text {a }}$ (29 de agosto de 2005). Tais ações não tiveram continuidade, já que durante a pesquisa constatamos que as regiões não têm um site específico de divulgação, nem conta com material promocional.

Quando o Salão de Turismo estava em operacionalização, a Setur, de forma conjunta com as regiões, preparava um material específico de cada polo para ser divulgado. No entanto, percebeu-se, através da leitura das atas, que mesmo nesse momento, as regiões turísticas tinham dificuldade de colaborar com tal material, existindo dificuldade, por exemplo, para que os representantes dos municípios enviassem fotografias com qualidade suficiente para serem reproduzidas.

Com a paralisação do Salão, não há qualquer iniciativa de divulgação das

\footnotetext{
${ }^{15}$ Representante do Polo Seridó, em entrevista concedida em 29 set. 2016.

${ }^{16}$ Representante do Polo Costa Branca, em entrevista concedida em 12 jul. 2016.
} 
regiões independentes do que o estado realiza, fazendo com que cada município faça sua divulgação individualmente, conforme se menciona: "Quando se trata de marketing cada um faz individualmente, cada qual fazendo a sua parte." ${ }^{17} \mathrm{Em}$ outra entrevista, o mesmo aspecto é ressaltado: "Não existe site da região, que promova o potencial da região, ainda se espera muito da Setur e os municípios recorrem a iniciativas pontuais." 18

Em virtude desses aspectos, a eficácia nesse indicador é considerada baixa em todas as regiões turísticas do Rio Grande do Norte, pois as ações realizadas pela Setur/Emprotur são pontuais, já que o Plano de Marketing estava na época da pesquisa ainda em elaboração; bem como o que é realizado pelos polos são estratégias de marketing diversas e individuais por parte de cada município.

O quarto indicador desse eixo - Sistematização de informações sobre evolução do turismo - cujo objetivo era mensurar se a implementação do PRT gerou um ambiente propício à coleta e ao armazenamento de dados sobre o turismo nas localidades, que pudessem produzir informações importantes e auxiliar no planejamento do turismo e no próprio acompanhamento do Programa.

Sobre essa questão dentro do PRT, no sexto módulo da primeira fase, previa-se um "Sistema de Informações do Programa" (BRASIL, 2007c), o qual deveria ser composto por seis subsistemas, entre os quais o Sistema de Monitoria e Avaliação (SMA), que não foi efetivado; o Cadastro dos Prestadores de Serviços Turísticos (Cadastur), cujo site continua em funcionamento; e o Inventário da Oferta Turística (Invtur), outro subsistema proposto. No caso do Rio Grande do Norte, questionamos aos atores entrevistados se havia a coleta de dados sobre a evolução do turismo nos municípios e regiões, e como esse processo se dava, no que obtivemos como resposta que as dificuldades de coleta e armazenamento de dados persistem no estado, não se considerando avanços a partir da implementação do PRT.

Essa problemática tomou uma dimensão maior quando se precisou dessas informações para a elaboração dos PDITSs. Constatamos quanto a isso que existiu dificuldade de comunicação entre as consultorias responsáveis pela elaboração desses documentos e os municípios, no que diz respeito a não disponibilização das informações necessárias por parte dos atores municipais. Esse fato foi notório quando assistimos às reuniões dos Conselhos de Turismo das regiões turísticas, no período de

\footnotetext{
${ }^{17}$ Representante do Polo Costa Branca, em entrevista concedida em 12 jul. 2016.

${ }^{18}$ Representante do Polo Seridó, em entrevista concedida em 08 jul. 2016.
} 
25 de agosto de 2016 a $1^{\circ}$ de setembro de 2016, quando tanto a Itec Infraestrutura, Tecnologia, Engenharia e Consultoria (responsável pela elaboração dos PDITS do Polo Agreste/Trairi e Polo Serrano) quanto a Solimar International (responsável pela elaboração do "Planejamento Estratégico e Marketing para o Turismo do Rio Grande do Norte") ressaltaram em todas as regiões as dificuldades de obter informações de alguns municípios, que não respondiam aos questionários enviados, mesmo após várias tentativas.

Sobre isso, podemos afirmar que verificamos durante a pesquisa que muitos dos atores municipais não possuem de fato os dados solicitados, o que é perceptível na fala: "Se o gestor da pasta, ele não conhece, qual a razão por que ele não conhece (?). Então se é preciso elaborar um trabalho, então você enquanto empresa precisa conhecer." 19

Como os dados realmente necessários não existem, busca-se utilizar aqueles que estão em disponibilidade. Um fato que agrava o problema da ausência de informações é que os planos precisam ser produzidos em um tempo curto, dificultando que essas empresas contratadas possam realizar uma pesquisa mais aprofundada nas fontes existentes ou mesmo que se pudesse produzir dados. Além disso, alguns municípios alegam receber várias vezes formulários que contêm as mesmas perguntas ou perguntas muito semelhantes, seja por parte das consultorias ou da Setur, indicando que não se mantém um banco de dados no âmbito do estado em que apenas se atualizasse as informações já armazenadas.

Sobre a ausência de dados nos municípios, verificou-se que por vezes algumas gestões produzem algumas informações, entretanto, elas são completamente ignoradas quando uma nova gestão assume a Prefeitura, o que acaba não dando continuidade à coleta, em que a série histórica poderia gerar conhecimentos basilares para o planejamento. Outras vezes, extraviam-se os poucos dados existentes.

Tal quadro indica que a eficácia desse indicador nas cinco regiões turísticas do Rio Grande do Norte é baixa, pois os dados atualmente existentes para todas as regiões foram compilados, apenas quando necessário, para a elaboração dos PDITSs, por um trabalho conjunto das consultorias e dos municípios. No âmbito estadual e municipal tem-se a mesma conjuntura, o que indica que a avaliação do PRT é prejudicada, já que os dados existentes são fragmentados e não permitem que se

\footnotetext{
${ }^{19}$ Representante do Polo Agreste/Trairi, em entrevista concedida em 14 set. 2016.
} 
tenham uma precisão quanto aos processos e resultados desse Programa nos âmbitos regionais e locais.

\section{Considerações finais}

Os resultados coletados durante o período pesquisado (2004-2014) mostram que foram elaborados três planos: Polo Costa Branca, Polo Costa das Dunas e Polo Seridó, sendo parcialmente implementados em virtude da ausência de recursos. Além disso, verificamos que a forma de elaboração desses documentos deve ser revista, para que se insiram efetivamente os atores e realidades locais, bem como é preciso garantir recursos para que as ações sejam implementadas.

Identificamos ainda que não existem nas regiões turísticas roteiros comercializados que tenham sido criados no âmbito do PRT, apesar de várias propostas terem surgido. Esse fato indica que o Programa não propiciou dinamização econômica nessas regiões como pretendeu. Além disso, identificou-se que as ações de cooperação são pontuais e contam com a predominância de alguns atores regionais.

Quanto às ações de marketing, verificamos que o plano estadual estava em elaboração no período pesquisado e que não existem esforços coordenados com o objetivo promocional conjunto no âmbito regional. 0 que existem são ações pontuais realizadas pelo estado e pelos municípios. Sobre a sistematização das informações, constatamos que tanto no âmbito estadual quanto no regional e municipal não se tem conseguido coletar os dados necessários ao planejamento do turismo, principalmente porque não se tem recursos, de várias ordens, para que essa atividade pudesse ser empreendida.

Tais resultados indicam que a eficácia do PRT, no âmbito regional, no Rio Grande do Norte é baixa na maior parte dos indicadores eleitos para a avaliação, concorrendo vários fatores para tal situação, no que a ausência de recursos financeiros, e consequentemente humanos, destacam-se perante outros intervenientes pesquisados. 


\section{Referências}

ARRETCHE, Marta. Tendências no estudo da avaliação. In: RICO, Elizabeth Melo (Org.). Avaliação de políticas sociais: uma questão em debate. 6. ed. São Paulo: Cortez: Instituto de Estudos Especiais, 2009.

BOULLÓN, Roberto C. Planejamento do espaço turístico. Bauru: Edusc, 2002.

BRASIL. Lei Geral do Turismo, $\mathrm{n}^{\circ} 11.771$ de 17 de setembro de 2008. Dispõe sobre a Política Nacional de Turismo, define as atribuiçõos do Governo Federal no planejamento, desenvolvimento e estímulo ao setor turístico; revoga a Lei $\mathrm{n}^{0}$ 6.505, de 13 de dezembro de 1977, o Decreto-Lei $\mathrm{n}^{0} 2.294$, de 21 de novembro de 1986, e dispositivos da Lei $n^{0} 8.181$, de 28 de março de 1991; e dá outras providências. Diário Oficial [da] República Federativa do Brasil, Brasília, 18 set. 2008. Disponível em: <http://www.planalto.gov.br/ccivil_03/_ato2007-2010/2008/lei//11771.htm>. Acesso em: 5 abr. de 2015.

BRASIL. Ministério do Turismo. Programa de Regionalização do Turismo: Diretrizes. Brasília: Ministério do Turismo, 2013.

BRASIL. Ministério do Turismo. Programa de Regionalização do Turismo - Roteiros do Brasil: Diretrizes Políticas. Ministério do Turismo. Brasília: Ministério do Turismo, 2004.

BRASIL. Ministério do Turismo. Programa de Regionalização do Turismo - Roteiros do Brasil: Introdução à Regionalização do Turismo. Brasília: Ministério do Turismo, 2007a. BRASIL. Ministério do Turismo. Programa de Regionalização do Turismo - Roteiros do Brasil: Módulo Operacional 8: Promoção e Apoio à Comercialização. Brasília: Ministério do Turismo, 2007b.

BRASIL. Ministério do Turismo. Programa de Regionalização do Turismo - Roteiros do Brasil: Módulo Operacional 6: Sistema de Informações do Programa. Brasília: Ministério do Turismo, 2007c.

COHEN, Ernesto; FRANCO, Rolando. Avaliação de projetos sociais. 9. ed. Petrópolis: Vozes, 2011.

CRUZ, Rita de Cássia Ariza da. Planejamento governamental do turismo: convergências e contradições na produção do espaço. In: LEMOS, Amalia Inés Geraiges de et al (Org.). América latina: cidade, campo e turismo. São Paulo. Clacso, 2006.

CRUZ, Rita de Cassia Ariza da. Política de turismo e território. 3. ed. São Paulo: Contexto, 2002.

DRAIBE, Sonia Miriam. Avaliação de implementação: esboço de uma metodologia de trabalho em políticas públicas. In: BARREIRA, M. C. R. N.; CARVALHO, M. C. B. (Org.). Tendências e perspectivas na avaliação de políticas e programas sociais. São Paulo: IEE/PUC-SP, 2001.

FIGUEIREDO, Marcos Faria; FIGUEIREDO, Argelina Maria Cheibub. Avaliação política e avaliação de políticas. Revista Análise \& Conjuntura, Belo Horizonte, v. 1, n. 3, p. 107-127, set./dez., 1986.

FRACTUCCI, Agnaldo Cesar. A Dimensão Espacial das Políticas Públicas de Turismo no Brasil. In: PIMENTEL, Thiago Duarte; EMMENDOERFER, Magnus Luiz; TOMAZZONI, Edegar Luis (Org.). Gestão pública do turismo no Brasil: teorias, metodologias e aplicações. 1. ed. Caxias do Sul: Educs, 2014.

FRACTUCCI, Agnaldo Cesar. A dimensão Espacial nas Políticas Públicas Brasileiras de Turismo: as possibilidades das redes regionais de turismo. Tese (Doutorado em Geografia) - Universidade Federal Fluminense, Niterói, 2008.

JANNUZZI, Paulo de Martino. Indicadores para diagnóstico, monitoramento e avaliação 
de programas sociais no Brasil. Revista do Serviço Público, Brasília, v. 56, n. 2, p. 137-160, abr./jun. 2005.

LIMA, Renata Mayara Moreira de. Turismo, políticas públicas e desenvolvimento: uma avaliação do programa de regionalização do turismo nas cinco regiões turísticas do Rio Grande do Norte (2004-2014). Tese (Doutorado em Ciências Sociais) - Programa de Pós-Graduação em Ciências Sociais, Universidade Federal do Rio Grande do Norte, 2017.

Recebido: 29 Jun 2021 Aceito: 20 Ago 2021 